\title{
Comprehensive analysis of T-cell receptor repertoire in patients with acute coronary syndrome by high-throughput sequencing
}

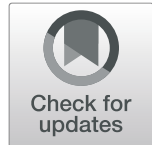

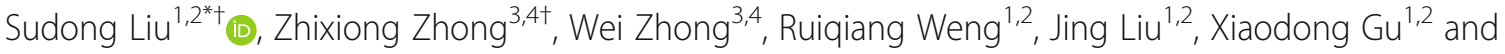
Yongyu Chen ${ }^{1,2}$

\begin{abstract}
Background: This study aims to investigate the T-cell receptor (TCR) repertoire in patients with acute coronary syndrome (ACS).

Methods: The TCR repertoires of 9 unstable angina patients (UA), 14 acute myocardial infarction patients (AMI) and 9 normal coronary artery (NCA) patients were profiled using high-throughput sequencing (HTS). The clonal diversity of the TCR repertoires in different groups was analyzed, as well as the frequencies of variable (V), diversity (D) and joining $(J)$ gene segments.

Results: ACS patients including UA and AMl, showed reduced TCRB diversity than NCA patients. ACS patients presented higher levels of clonal expansion. The clonotype overlap of complementarity determining region 3(CDR3) was significantly varied between different groups. A total of $10 \mathrm{~V}$ genes and $1 \mathrm{~J}$ gene were differently utilized between ACS and NCA patients. We identified some shared CDR3 amino acid sequences that were presented in ACS but not in NCA patients.

Conclusions: This study revealed the distinct TCR repertoires in patients with ACS and demonstrated the presence of disease associated T-cell clonotypes. These findings suggested a role of T cells in ACS and provided a new way to explore the mechanisms of ACS.
\end{abstract}

Keywords: Acute coronary syndrome (ACS), T-cell receptor (TCR), Clonotype, High-throughput sequencing (HTS)

\section{Background}

Acute coronary syndrome (ACS) is the severe form of coronary artery disease (CAD), which remains the leading cause of morbidity and mortality worldwide [1]. It has been well documented that atherosclerosis, the major cause of $\mathrm{CAD}$, is a chronic inflammatory process

\footnotetext{
* Correspondence: vanguard_1987@163.com

†'Sudong Liu and Zhixiong Zhong contributed equally to this work.

'Clinical Core Laboratory, Meizhou People's Hospital (Huangtang Hospital), Meizhou Hospital Affiliated to Sun Yat-sen University, No 63 Huangtang Road, Meijiang District, Meizhou 514031, P. R. China

${ }^{2}$ Guangdong Provincial Key Laboratory of Precision Medicine and Clinical Translational Research of Hakka Population, Meizhou 514031, P. R. China Full list of author information is available at the end of the article
}

involving a variety of innate and adaptive immune components [2, 3]. T cells are prominent component in the atherosclerotic plaque, and typical signs of $\mathrm{T}$ cell activation were observed in the blood of patients with ACS [4-6]. Evidence suggested that ACS patients had higher frequency and enhanced function of T cells compared to patients with stable angina (SA) [7]. Therefore, $\mathrm{T}$ cells mediated adaptive immunity may play an important role in the pathological process of ACS.

Atherosclerosis which is featured by the formation of plaques containing immune cells, foam cells and others components is suggested as the most important pathogenic mechanism of ACS [8]. Previous study has found

(c) The Author(s). 2020 Open Access This article is licensed under a Creative Commons Attribution 4.0 International License, which permits use, sharing, adaptation, distribution and reproduction in any medium or format, as long as you give appropriate credit to the original author(s) and the source, provide a link to the Creative Commons licence, and indicate if changes were made. The images or other third party material in this article are included in the article's Creative Commons licence, unless indicated otherwise in a credit line to the material. If material is not included in the article's Creative Commons licence and your intended use is not permitted by statutory regulation or exceeds the permitted use, you will need to obtain permission directly from the copyright holder. To view a copy of this licence, visit http://creativecommons.org/licenses/by/4.0/. The Creative Commons Public Domain Dedication waiver (http://creativecommons.org/publicdomain/zero/1.0/) applies to the data made available in this article, unless otherwise stated in a credit line to the data. 
that $\mathrm{T}$ cells accumulated in human atherosclerotic plaques, most of which were effector and memory $\mathrm{T}$ cells [9]. Meanwhile, researchers have demonstrated the existence of $\mathrm{T}$ cells within the aortic adventitia of vessels [10]. Accumulating evidences suggest that $T$ cells play an important role in the immunological mechanisms of the ACS $[11,12]$. However, the clonotype feature of involved $\mathrm{T}$ cells remained unclarified.

$\mathrm{T}$ cell receptor (TCR) expressed on the surface of $\mathrm{T}$ cells recognizes the antigenic peptides presented by antigen presented cells (APC). Human TCRs are commonly composed of $\alpha$ and $\beta$ chains [13]. TCR $\alpha$ chains consist of variable $(\mathrm{V})$, joining $(\mathrm{J})$ and constant $(\mathrm{C})$ regions, while TCR $\beta$ chains consist of $\mathrm{V}, \mathrm{J}, \mathrm{C}$ and diversity (D) regions. The diversity of TCR is generated by rearrangement of the V, D, J and C regions. Random insertions and deletions of nucleotides at the junctions increase the diversity [14]. The alteration of TCR repertoire has been observed in many diseases, such as cancer, autoimmune disorders and infectious diseases [15, 16]. Thus, TCR repertoire has great diagnosis value and clinical utility, as its diversity reflects the state of immune system [17]. Researchers begin to explore the association between changes in TCR repertoire and diseases, on propose to identify novel biomarkers or prognostic factors $[18,19]$.

In the present study, we aimed to characterize the TCR repertoire in peripheral blood samples from ACS patients using high-throughput sequencing. We analyzed the diversity of the TCR repertoire, V/J gene utilization and disease associated TCR $\beta$ clonotypes. The present study might contribute to the understanding of the roles of $\mathrm{T}$ cells in ACS development and provides a new way to explore the mechanisms of ACS.

\section{Methods}

\section{Subjects}

Patients were enrolled from Cardiology Department of Meizhou People's Hospital (Huangtang Hospital), Meizhou Academy of Medical Sciences, Meizhou Hospital Affiliated to Sun Yat-sen University, Meizhou, China. Patients were diagnosed as UA if they had: (1) anginalike chest pain or ischemic equivalent; (2) electrocardiographic abnormalities compatible on at least two contiguous leads; (3) at least one major pericardial vessel with $>70 \%$ stenosis. Patients were diagnosed as AMI if met the above 3 criterions plus another one: (4) abnormalities above the upper normal limit for myocardial necrosis biomarkers (troponin and/or CKMB). Normal coronary artery (NCA) patients were defined as no stenosis in coronary arteries by quantitative coronary angiography and served as controls in this study. Patients were excluded if they had the following manifestations or diseases, i.e. left ventricular ejection fraction $\leq 45 \%$, congestive heart failure, chronic kidney or hepatic disease and cancer. The diagnosis was made by two senior cardiologists. This study was approved by the Ethics Committee of the Meizhou People's Hospital (Huangtang Hospital). Each patient had signed a written informed consent.

\section{Sample collection}

Peripheral venous blood samples were collected and placed in EDTA-coated tubes. The blood samples were processed within $30 \mathrm{~min}$. PBMCs were isolated from fresh whole blood by density gradient centrifugation using Hypaque-Ficoll (GE Healthcare Bio-sciences AB, Sweden). The isolated PBMCs were lysed using TRIzol reagent (Invitrogen, USA) and stored at $-80^{\circ} \mathrm{C}$ until used.

\section{RNA extraction and CDNA synthesis}

Total RNA was extracted from $1 \times 10^{6}$ PBMCs from each sample using RNeasy Mini Kit (QIAGEN, German) following the manufacture's protocol. The concentrations and purity of RNA were measured by Nanodrop 1000 spectrophotometer (Thermo FisherScientific Inc., USA).RNA integrity was analyzed by the Bioanalyzer 2100 system (Agilent Technologies, USA). cDNA libraries were prepared by $5^{\prime}$-rapid amplification of cDNA ends (RACE) using the SMARTer PCR cDNA synthesis kit (Clontech, USA) as described previously [20]. Briefly, $1.5 \mu \mathrm{g}$ of total RNA was mixed with the primer $\mathrm{BC} 1 \mathrm{R}$ (CAGTATCTGGAGTCATTGA) $(20 \mu \mathrm{M})$ in a sterile thin-walled reaction tube. The tube was placed on a thermal cycler and incubated for $3 \mathrm{~min}$ at $70^{\circ} \mathrm{C}$ and then for $2 \mathrm{~min}$ at $42{ }^{\circ} \mathrm{C}$ to anneal synthesis primer. A reaction mix containing first strand buffer, $5^{\prime}$-template switch adapter and SMARTScribe reverse transcriptase was prepared and added to the tube. The tube was incubated at $42{ }^{\circ} \mathrm{C}$ for $60 \mathrm{~min}$.

\section{Library construction and sequencing}

Libraries were prepared using two-round PCR with specific primers as reported previously [20]. Briefly, in the first-run PCR amplification, the reaction system containing cDNA, Advantage 2 polymerase mix (Clontech, USA), universal primer smart 20 (CACTCTATCC GACAAGCAGTGGTATCAACGCAG), and TCR $\beta$ specific primer (TGCTTCTGATGGCTCAAACAC) was prepared. TCR $\beta$ was amplified using LightCycler 480 (Roche, USA) with the following program: $95^{\circ} \mathrm{C}$ for $20 \mathrm{~s}$, $65^{\circ} \mathrm{C}$ for $20 \mathrm{~s}, 72^{\circ} \mathrm{C}$ for $50 \mathrm{~s}$, for a total of 18 cyclers. The products were purified using the QIAquick PCR purification kit (Qiagen, German).

In the second-run PCR, the reaction system was prepared containing the purified products, universal primers Step1(CACTCTATCCGACAAGCAGT), specific primer hum-bcj (ACACSTTKTTCAGGTCCTC). Amplification was carried out on LightCycler 480 with 
the following program: $95^{\circ} \mathrm{C}$ for $20 \mathrm{~s}, 65^{\circ} \mathrm{C}$ for $20 \mathrm{~s}$, $72{ }^{\circ} \mathrm{C}$ for $50 \mathrm{~s}$, for a total of 12 cycles. The products were purified as above. Libraries were amplified using Illumina sequencing primers with barcodes. Then, pairedend $150 \mathrm{bp}$ sequencing was performed on the Illumina HiSeq2000 platform in ShenZhen Realomics Inc.

\section{Bioinformatic analysis}

The sequencing quality of the library by Illumina Hiseq 2000 was evaluated by the Realomics system formula. Briefly, the adaptor reads and the low-quality reads were filtered to obtain clean data. Subsequently, the clean data was aligned to human IGH database and analyzed by miXCR [21]. The high-quality reads were further assembled into clonotypes, correcting for PCR and sequencing errors using a heuristic multilayer clustering by VDJ tool $[22,23]$.

\section{Statistical analysis}

The data were analyzed with IBM SPSS 20.0 software (Social Science Statistics Software Package). Continuous data were presented as means \pm standard deviation (SD) and categorical variables were presented as number (\%). Data were assessed for their normality using Kolmogorov-Smirnov test. One-way analysis of variance (ANOVA) was used for normally distributed data, and Wilcoxon rank-sum test was used for data did not follow a normal distribution. For the categorical variables, Chi-square test was performed. $P<0.05$ was considered statistically significant.

\section{Results}

\section{Profile of TCR $\beta$ CDR3 in ACS patients}

Our study cohort consisted of 9 NCA, 9 UA and 14 AMI patients. The clinical characteristics of participants are shown in Table 1. There is not significant difference in age and gender, as well as lipid levels between different groups. As for medicine use, UA and AMI patients take more statins, ACEI/ARB and $\beta$-blocker than NCA patients.

We obtained a total number of 459,866,341 clean reads, with an average of $14,370,823$ for each sample. We identified 51 distinct $\mathrm{V} \beta$ gene segments and 14 distinct $J \beta$ gene segments among the participants. No difference was observed in the TCR $\beta$ V gene composition between different groups (Supporting Fig. S1). A detailed description of sequencing data including total clean reads, clones, unique $\mathrm{V}$ genes and other information are presented in Supporting Table S1.

\section{A reduced TCR $\beta$ CDR3 diversity in ACS patients}

The percentage of the productive unique TCR $\beta$ sequence provides a general assessment of sample diversity. As shown in Fig.1a, the percentage of the productive unique TCR $\beta$ sequence in AMI patients $(2.35 \% \pm 0.82 \%)$ and UA patients $(3.08 \% \pm 2.59 \%)$ were both significantly lower than that in NCA $(5.70 \% \pm$ $3.65 \%)$, but there was no significant difference between AMI and UA. The expansion level of each unique clone was another major measurement for immune diversity. Clonal expansion was assessed by cumulative percentage

Table 1 Clinical Characteristics of study subjects for this study

\begin{tabular}{|c|c|c|c|c|}
\hline Variables & $\mathrm{NCA}(n=9)$ & UA $(n=9)$ & AMI $(n=14)$ & $\boldsymbol{P}$ value \\
\hline Age, years & $55.4 \pm 6.95$ & $56.1 \pm 5.46$ & $59.86 \pm 6.76$ & 0.28 \\
\hline Gender (F/M) & $5 / 4$ & $5 / 4$ & $8 / 6$ & 0.99 \\
\hline Current smoking, n (\%) & $2(22.2 \%)$ & $2(22.2 \%)$ & $4(28.6 \%)$ & 0.91 \\
\hline Triglycerides, mmol/L & $1.36 \pm 0.56$ & $1.71 \pm 0.56$ & $1.98 \pm 1.19$ & 0.49 \\
\hline Cholesterol, mmol/L & $4.85 \pm 1.00$ & $5.26 \pm 1.23$ & $4.69 \pm 1.48$ & 0.58 \\
\hline $\mathrm{HDL}, \mathrm{mmol} / \mathrm{L}$ & $1.25 \pm 0.27$ & $1.25 \pm 0.24$ & $1.11 \pm 0.24$ & 0.30 \\
\hline LDL, mmol/L & $2.66 \pm 0.62$ & $3.01 \pm 0.76$ & $2.64 \pm 0.80$ & 0.47 \\
\hline \multicolumn{5}{|l|}{ Medicine use } \\
\hline Nitrate esters drug, n (\%) & 0 & $1(11.1 \%)$ & 0 & 0.26 \\
\hline Clopidogrel, n (\%) & $1(11.1 \%)$ & $5(55.6 \%)$ & $5(35.7 \%)$ & 0.08 \\
\hline Statins, n (\%) & 0 & $6(66.7 \%)$ & $1(7.1 \%)$ & $<0.01$ \\
\hline Aspirin, n (\%) & $2(22.2 \%)$ & $7(77.8 \%)$ & $6(42.9 \%)$ & 0.06 \\
\hline ACEI/ARB, n (\%) & 0 & $4(44.4 \%)$ & $1(7.1 \%)$ & 0.01 \\
\hline $\mathrm{Ca}_{2}{ }^{+}$antagonist, $\mathrm{n}(\%)$ & 0 & $2(22.2 \%)$ & 0 & 0.06 \\
\hline$\beta$ - blocker, n (\%) & $1(11.1 \%)$ & $6(66.7 \%)$ & 0 & $<0.01$ \\
\hline
\end{tabular}

HDL High-density lipoprotein;

LDL Low-density lipoprotein;

ACEI/ARB Angiotensin-converting enzyme inhibitors/angiotensin antibody;

${ }^{a}$ comparison between three groups using one-way ANOVA or Chi-square 
a
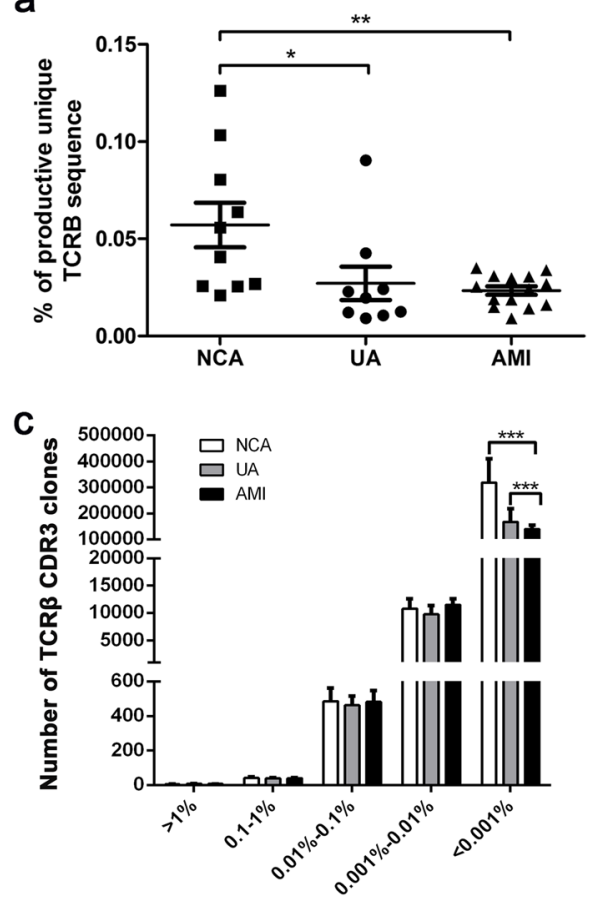

b

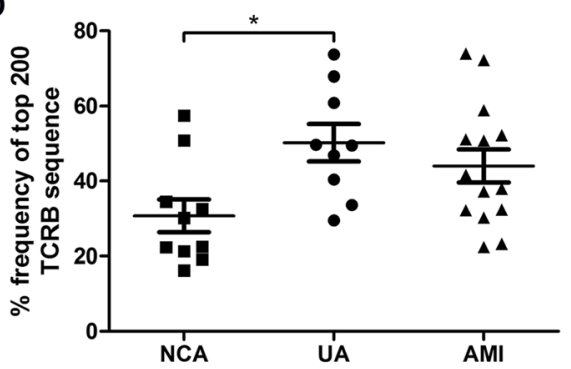

d

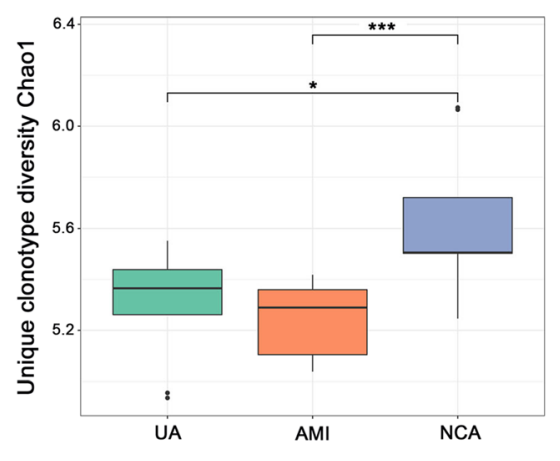

Fig. 1 Clonal distribution of T cells in patients with UA, AMI and NCA. a Frequency of unique TCR $\beta$ sequences identified in the peripheral blood of patients with UA, AMI and NCA. Differences between groups were compared using one-way ANOVA. b Percentage frequency of top 200 TCR $\beta$ nucleotide sequences in UA, AMI and NCA. Differences between groups were compared using one-way ANOVA. c Frequency distributions of TCRß CDR3 clones from UA $(n=9), \operatorname{AMI}(n=14)$ and NCA $(n=9)$ patients. Differences between groups were compared using one-way ANOVA. $\mathbf{d}$ Diversity metrics for TCR $\beta$ CDR3 repertoires in UA, AMI and NCA. Data were compared using Wilcoxon rank-sum test. ${ }^{*} P<0.05$, ${ }^{*} P<0.01,{ }^{* * *} P<0.001$

of the repertoire. The average fraction of the top 200 TCR $\beta$ sequences was $30.72 \%$ in NCA, $51.47 \%$ in UA, and $44.02 \%$ in AMI, suggesting a clonal expansion of TCR $\beta$ nucleotide sequences in UA and AMI patients (Fig. 1b). The number of TCR $\beta$ CDR3 clones were similar between different groups, except for the low frequent clones (Fig. 1c). Finally, the diversity of TCR $\beta$ CDR3 was assessed by Chao 1 approach. It was suggested that diversity of $\mathrm{T}$ cell clones significantly decreased in AMI and UA patients as compared to NCA (Fig. 1d).

\section{The usage patterns of $V \beta$ and $J \beta$ gene segments in ACS patients}

The frequency heatmap of $\mathrm{V} \beta$ and $\mathrm{J} \beta$ genes showed the distribution patterns of $\mathrm{V} \beta$ and $\mathrm{J} \beta$ in NCA, UA and AMI patients (Fig. 2 and Supporting Fig. S2). Frequencies of most $V \beta$ and $J \beta$ genes were similar between different groups, apart from some $\mathrm{V} \beta$ and $\mathrm{J} \beta$ gene. In AMI, $10 \mathrm{~V} \beta$ clonotypes were differentially used compared with NCA, and all of them showed lower frequencies except TRBV2 (Fig. 3a). In UA, TRBV12-3 and TRBV2 were more frequent than in NCA, while TRBV10-3, TRBV19, TRBV25-1, TRBV5-7 and TRBV7-8 were less frequent (Fig. 3b). In AMI patients, TRBV12-3 was more frequent than in UA (Fig. 3c). In addition, TRBJ2-1 was more frequent in UA and AMI than that in NCA (Fig. 3d).

\section{TCR $\beta$ clonotype overlap within and between different groups}

We next investigated TCR $\beta$ clonotype overlap in patients of the same group and TCR $\beta$ clonotype overlap between different groups. The average TCR $\beta$ clonotype overlap in UA and AMI patients were significantly lower than that in NCA patients $(P<0.001$ and $P<0.05)$. The average TCR $\beta$ clonotype overlap in UA patients was lower than that in AMI patients $(P<0.05)$ (Fig. 4a). However, the TCR $\beta$ clonotype overlap between two groups remained very low, and did not show any difference (Fig. 4b). Collectively, these data suggested a greater sharing of TCR $\beta$ repertoire in NCA patients in compared to the AMI and UA patients.

\section{Presence of disease-associated clonotypes in UA and AMI} patients

To determine the immune response characteristics specific to ACS, we searched for TCR $\beta$ clonotypes that were presented in UA or AMI patients but NCA patients. We 



Fig. 2 Heatmap of $V \beta$ and $J \beta$ gene segments usage in samples from UA, AMl and NCA. The heatmap bar indicates the usage frequency of V $\beta$ or $J \beta$ gene segments in each sample

identified 3 TCR $\beta$ CDR3 clonotypes that were frequent in UA patients but absent in NCA patients. There were 9 TCR $\beta$ CDR3 clonotypes that were frequent in AMI patients but rare in NCA patients. In addition, we found 5 TCR $\beta$ CDR3 clonotypes that were frequently shared in both UA and AMI patients, while scarcely presented in NCA patients (Table 2). A total of 28 TCR $\beta$ CDR3 clonotypes were specifically frequent in AMI patients, and additional 30 TCR $\beta$ CDR3 clonotypes were specifically frequent in UA patients (Supporting Table S2 and S3). These data suggested the presence of disease-associated TCR $\beta$ CDR3 clonotypes in UA and AMI.

\section{Discussion}

Although modern medical treatment has considerably improved the outcome of ACS, it is still the deadliest disease all around the world [24]. In this study, we comprehensively analyzed the TCR CDR3 $\beta$ repertoire of patients with UA, AMI and NCA. The results suggested that: (1) diversity of $\mathrm{T}$ cell clones was reduced in patients with UA and AMI; (2) the $\mathrm{V} \beta$ and $J \beta$ genes usage patterns differed in UA, AMI and NCA; (3) diseaseassociated TCR CDR3 $\beta$ clonotypes were identified.

$\mathrm{T}$ cell-mediated immune responses are principal component of cellular immune response and protected against many diseases and infections $[25,26]$. Previous studies have found a higher level of activated T-cells in ACS patients as compared with stable angina patients $[5,6]$. ApoE ${ }^{-1-}$ mice lacking $\mathrm{CD} 4+\mathrm{T}$ cells were found less susceptible to atherosclerosis compared with wild-type mice, and transfer of CD4+ $\mathrm{T}$ cells to immunodeficient $\mathrm{ApoE}^{-/-}$mice significantly 

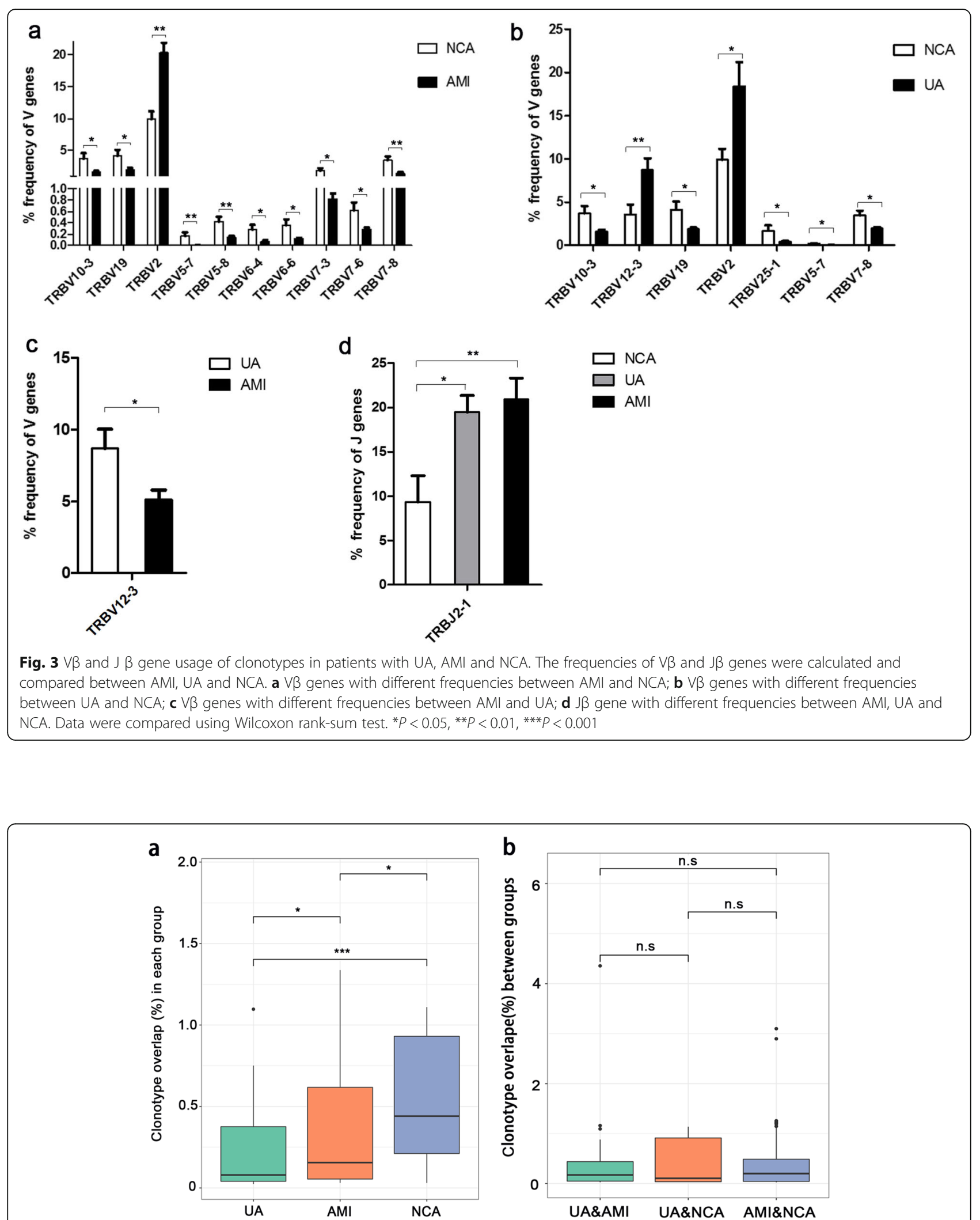

Fig. 4 Overlap in T-cell specificity in each group and between disease groups. a Data show the overlap of clonotypes in each disease group, UA, AMI and NCA. $\mathbf{b}$ Data show the overlap of clonotypes between disease groups, UA and AMI, UA and NCA, AMI and NCA. Data were compared using Wilcoxon rank-sum test. ${ }^{*} P<0.05$, ${ }^{* *} P<0.01,{ }^{* * *} P<0.001$ 
Table 2 Shared TCR $\beta$ CDR3 clonotypes in ACS patients

\begin{tabular}{|c|c|c|c|c|c|c|}
\hline \multirow[t]{2}{*}{ TCR $\beta$ CDR3 } & \multicolumn{2}{|l|}{ NCA } & \multirow{2}{*}{$\begin{array}{l}\text { UA } \\
\text { Case }\end{array}$} & \multicolumn{3}{|l|}{ AMl } \\
\hline & Case & Frequency & & Frequency & Case & Frequency \\
\hline \multicolumn{7}{|l|}{ UA } \\
\hline CASSRTSGGYNEQFF & 0/9 & NA & $8 / 9$ & $5.94 \mathrm{E}-07$ & $8 / 14$ & $1.07 \mathrm{E}-06$ \\
\hline CASSAGRETQYF & $0 / 9$ & NA & $7 / 9$ & 4.64E-07 & $6 / 14$ & $1.26 \mathrm{E}-05$ \\
\hline CASSLTSGLYNEQFF & 0/9 & NA & $7 / 9$ & 5.59E-06 & $3 / 14$ & $9.51 \mathrm{E}-07$ \\
\hline CASSPSGGQETQYF & $1 / 9$ & $3.52 \mathrm{E}-08$ & $7 / 9$ & 7.50E-06 & $10 / 14$ & $3.63 \mathrm{E}-06$ \\
\hline \multicolumn{7}{|l|}{ AMI } \\
\hline CASSLGGRALEQFF & $1 / 9$ & $3.25 \mathrm{E}-08$ & $4 / 9$ & $6.83 \mathrm{E}-07$ & $11 / 14$ & $6.14 \mathrm{E}-05$ \\
\hline CASSKTSGRAFEQFF & $1 / 9$ & $3.25 \mathrm{E}-08$ & $3 / 9$ & 4.53E-07 & $10 / 14$ & 4.01E-07 \\
\hline CATSRDGGVTNQYF & $1 / 9$ & $1.62 \mathrm{E}-08$ & $4 / 9$ & $3.19 \mathrm{E}-05$ & $10 / 14$ & $2.30 \mathrm{E}-07$ \\
\hline CASSVPLRLAESSYNEQFF & $1 / 9$ & 7.77E-08 & $4 / 9$ & $1.49 \mathrm{E}-06$ & $10 / 14$ & $2.63 \mathrm{E}-04$ \\
\hline CASSTGQEQYF & $1 / 9$ & $2.20 \mathrm{E}-07$ & $3 / 9$ & $2.72 \mathrm{E}-07$ & $10 / 14$ & $3.41 \mathrm{E}-05$ \\
\hline CASSPHDQETQYF & $1 / 9$ & $1.10 \mathrm{E}-07$ & $4 / 9$ & $5.78 \mathrm{E}-07$ & $10 / 14$ & 2.64E-07 \\
\hline CASSPQGEVGYTF & $1 / 9$ & $1.62 \mathrm{E}-08$ & $4 / 9$ & $2.46 \mathrm{E}-07$ & $10 / 14$ & $1.93 \mathrm{E}-07$ \\
\hline CASRPGRGPDTQYF & $1 / 9$ & $1.55 \mathrm{E}-08$ & $4 / 9$ & $3.61 \mathrm{E}-07$ & $10 / 14$ & $2.48 \mathrm{E}-07$ \\
\hline CASSPSGGQETQYF & $1 / 9$ & $3.52 \mathrm{E}-08$ & $7 / 9$ & 7.50E-06 & $10 / 14$ & $3.63 \mathrm{E}-06$ \\
\hline \multicolumn{7}{|l|}{ UA\&AMI } \\
\hline CASSPSGGQETQYF & $1 / 9$ & $3.52 \mathrm{E}-08$ & $7 / 9$ & $7.50 \mathrm{E}-06$ & $10 / 14$ & $3.63 \mathrm{E}-06$ \\
\hline CASSLSGGSYNEQFF & $3 / 9$ & $2.78 \mathrm{E}-06$ & $7 / 9$ & 2.60E-08 & $10 / 14$ & $2.19 \mathrm{E}-07$ \\
\hline CASSYSYNEQFF & $3 / 9$ & $3.80 \mathrm{E}-08$ & $7 / 9$ & 4.08E-06 & $10 / 14$ & $4.54 \mathrm{E}-06$ \\
\hline CASRDRGSTDTQYF & $3 / 9$ & $5.73 \mathrm{E}-07$ & $7 / 9$ & 5.49E-04 & $10 / 14$ & 4.80E-07 \\
\hline CASSQTNQETQYF & $3 / 9$ & $1.26 \mathrm{E}-07$ & $7 / 9$ & $3.23 \mathrm{E}-06$ & $10 / 14$ & $6.76 \mathrm{E}-07$ \\
\hline
\end{tabular}

${ }^{\text {aThe same sequence }}$

promoted atherosclerosis. These findings suggested a proatherosclerotic role of $\mathrm{CD} 4+\mathrm{T}$ cells. The function of CD4+ T cells was proved exerted by production of IFN- $\gamma[27,28]$. Another study focused on the TCR $\gamma \delta$ $\mathrm{T}$ repertoire suggested that clonal expansion of $\gamma \delta \mathrm{T}$ cell and altered expression of IL-17A was associated with the clinical outcome of AMI [29]. Regulatory T cell (Treg) has been shown to induce regression of atherosclerosis and to increase plaque stability in mice [30]. Treg produced anti-inflammatory cytokines such as IL-10 and TGF $\beta$, thus prevented disease progression of atherogenesis [31]. Another study showed that the dysregulation of helper $\mathrm{T}$ cells impacted the immune response and impaired the stability of plaque in ACS patients [7]. However, there are still many unsolved problems regarding the $\mathrm{T}$ cells in procession of ACS.

The CDR3 region represents the uniqueness of each TCR and thus used as TCR signature or barcode [32]. Diversified TCRs were required for an intense adaptive immune responses, while pressures from both internal and external help shape the diversity of TCR [33, 34]. The TCR repertoire of patients with atherosclerosis has been investigated and level of diversity was reduced in
AS plaques [35]. In the present study, we found that clonal diversity of the TCR CDR3 $\beta$ decreased in ACS patients as compared to NCA. Meanwhile, a higher percentage of frequent clones (the top 200 TCR $\beta$ ) were observed in ACS patients, especially in UA. Additionally, we found that the average overlap between ACS and NCA was significantly different. Collectively, these data reflected that clonal expansion of $\mathrm{T}$ cells occurred in ACS patients.

Many local autoantigens contribute to these immunoregulatory abnormalities, resulting in the clonal restriction of $\mathrm{T}$ cells [36]. This restriction is associated with the plaque instability and inflammatory response [37]. Researchers have found oxidative low density lipid (ox-LDL) specific $\mathrm{T}$ cells and oligoclonal $\mathrm{T}$ cells in atherosclerotic lesions [38]. T cells expressing $V \beta 6$ were significantly proliferated in atherosclerotic plaques and responsible for ox-LDL recognition [39]. In our study, we observed that frequencies of $11 \mathrm{~V}$ gene segments and $1 \mathrm{~J}$ gene segment were altered in ACS patients compared to NCA.

The numbers and types of $\mathrm{T}$ cell clones containing different TCR amino acid/nucleic acid sequences are extremely large. Many techniques used in most of the 
previous studies are difficult to accurately reveal the features of TCR $\beta$ CDR3 clonotypes [40]. The immune repertoire sequencing technology used in our study is based on the multiplex PCR and next-generation sequencing, and much sensitive than previous method [41]. Meanwhile, we characterized the receptor signatures of $\mathrm{T}$ cells from ACS patients without any in vitro manipulation, thus avoided bias and obtained a near in vivo result.

\section{Conclusions}

In summary, the present study investigated a comprehensive characterization of TCR $\beta$ CDR3 repertoire in patients with UA, AMI and NCA. Our data suggested T cell diversity was significantly altered in ACS compared with NCA, and we identified some shared TCR $\beta$ clonotypes which were disease-associated. These results facilitate to improve our understanding of ACS and provide a new sight to explore the mechanism of this disease.

\section{Supplementary information}

Supplementary information accompanies this paper at https://doi.org/10. 1186/s12872-020-01538-6.

Additional file 1: Figure S1. Numbers of TRBV gene segments used in patients with UA, AMI and NCA

Additional file 2: Figure S2. $V \beta$ gene usage of clonotypes in the patients with UA, AMI and NCA. Data show the percentage frequency of $\checkmark$ genes used by clonotypes in the patients with UA, AMI and NCA.

Additional file 3: Figure S3. J $\beta$ gene usage of clonotypes in the patients with UA, AMI and NCA. Data show the percentage frequency of $J$ genes used by clonotypes in the patients with UA, AMI and NCA.

Additional file 4: Table S1. Detailed immune repertoire sequencing data. Table S2. Frequent unique TCR 3 CDR3 aa clonotypes in AMI patients. Table S3. Frequent unique TCR $\beta$ CDR3 aa clonotypes in UA patients.

\section{Abbreviations}

ACS: Acute coronary syndrome; ANOVA: One-way analysis of variance; CAD: Coronary artery disease; CDR3: Complementarity determining region 3 (CDR3); HTS: High-throughput sequencing; NCA: Normal coronary artery; PBMC: Peripheral blood mononuclear cell; SA: Stable angina; TCR: T-cell receptor

\section{Acknowledgements}

We would like to acknowledge the patients for their participation in this study and the dedicated staff of Center for Cardiovascular Diseases.

\section{Authors' contributions}

$S L$ conceived and designed the experiments, provided the fund, wrote the manuscript; ZZ and WZ enrolled patients and analyzed data; RW, JL and XG collection samples and conducted the experiments; YC collected clinical data and help review manuscript. All authors read and approved the final manuscript.

\section{Funding}

This study was supported by Science and Technology Program of Meizhou (Grant No.:2018B027), Key Scientific and Technological Project of Meizhou People's Hospital (Grant No.: MPHKSTP-20170101).

\section{Availability of data and materials}

The datasets used and/or analyzed during the current study available from the corresponding author on reasonable request.

\section{Ethics approval and consent to participate}

This study was conducted in accordance with the declaration of Helsinki. This study was conducted with approval from the Ethics Committee of the Meizhou People's Hospital (Huangtang Hospital), Meizhou Academy of Medical Sciences, Meizhou Hospital Affiliated to Sun Yat-sen University (NO:MPH-HEC 2018-A-36). Written informed consent was obtained from each patient.

\section{Consent for publication}

Not applicable.

\section{Competing interests}

The authors declare that they have no competing interests.

\section{Author details}

${ }^{1}$ Clinical Core Laboratory, Meizhou People's Hospital (Huangtang Hospital), Meizhou Hospital Affiliated to Sun Yat-sen University, No 63 Huangtang Road, Meijiang District, Meizhou 514031, P. R. China. ${ }^{2}$ Guangdong Provincial Key Laboratory of Precision Medicine and Clinical Translational Research of Hakka Population, Meizhou 514031, P. R. China. ${ }^{3}$ Center for Precision Medicine, Meizhou People's Hospital (Huangtang Hospital), Meizhou Hospital Affiliated to Sun Yat-sen University, Meizho 514031, P. R. China. ${ }^{4}$ Center for Cardiovascular Diseases, Meizhou People's Hospital (Huangtang Hospital), Meizhou Hospital Affiliated to Sun Yat-sen University, Meizhou 514031, P. R. China.

Received: 16 May 2019 Accepted: 18 May 2020 Published online: 27 May 2020

\section{References}

1. Oerlemans MI, Mosterd A, Dekker MS, de Vrey EA, Van MA, Pasterkamp G, Doevendans PA, Hoes AW, Sluijter JP. Early assessment of acute coronary syndromes in the emergency department: the potential diagnostic value of circulating microRNAs. EMBO Mol Med. 2012;4(11):1176-85.

2. Hansson GK, Hermansson A. The immune system in atherosclerosis. Nat Immunol. 2011;12(3):204-12.

3. Libby P, Lichtman A, Hansson G. Immune effector mechanisms implicated in atherosclerosis: from mice to humans. Immunity. 2013;38(6):1092-104.

4. Zhou X, Nicoletti A, Elhage R, Hansson GK. Transfer of CD4+ T cells aggravates atherosclerosis in Immunodeficient Apolipoprotein E knockout mice. Atherosclerosis. 2000;151(24):2919-22.

5. Liuzzo G, Goronzy JJ, Yang H, Kopecky SL, Holmes DR, Frye RL, Weyand CM. Monoclonal T-cell proliferation and plaque instability in acute coronary syndromes. Circulation. 2000;101(25):2883-8.

6. Liuzzo G, Kopecky SL, Frye RL, O'Fallon WM, Maseri A, Goronzy JJ, Weyand CM. Perturbation of the T-cell repertoire in patients with unstable angina. Circulation. 1999;100(21):2135-9..

7. Flego D, Liuzzo G, Weyand CM, Crea F. Adaptive immunity Dysregulation in acute coronary syndromes: from cellular and molecular basis to clinical implications. J Am Coll Cardiol. 2016;68(19):2107-17.

8. Ross R. Atherosclerosis--an inflammatory disease. N Engl J Med. 1999;340(2): $115-26$.

9. Stemme S, Holm J, Hansson GK. T lymphocytes in human atherosclerotic plaques are memory cells expressing CD45RO and the integrin VLA-1. Arterioscler Thromb. 1992;12(2):206-11.

10. Galkina E, Kadl A, Sanders J, Varughese D, Sarembock IJ, Ley K. Lymphocyte recruitment into the aortic wall before and during development of atherosclerosis is partially L-selectin dependent. J Exp Med. 2006;203(5): 1273-82.

11. Ross R. The pathogenesis of atherosclerosis: a perspective for the $1990 \mathrm{~s}$. Nature. 1993;362(6423):801-9.

12. Wick $G$, Schett $G$, Amberger $A$, Kleindienst $R, X u$ Q. Is atherosclerosis an immunologically mediated disease? Immunol Today. 1995;16(1):27-33.

13. Hogquist KA, Jameson SC, Heath WR, Howard JL, Bevan MJ, Carbone FR. T cell receptor antagonist peptides induce positive selection. Cell. 1994;76(1): $17-27$.

14. Warren RL, Freeman JD, Zeng T, Choe G, Munro S, Moore R, Webb JR, Holt RA. Exhaustive T-cell repertoire sequencing of human peripheral blood samples reveals signatures of antigen selection and a directly measured repertoire size of at least 1 million clonotypes. Genome Res. 2011;21(5):790-7. 
15. van Heijst JW, Ceberio I, Lipuma LB, Samilo DW, Wasilewski GD, Gonzales AM, Nieves JL, Mr VDB, Perales MA, Pamer EG. Quantitative assessment of T cell repertoire recovery after hematopoietic stem cell transplantation. Nat Med. 2013;19(3):372-7.

16. Jia Q, Zhou J, Chen G, Shi Y, Yu H, Guan P, Lin R, Jiang N, Yu P, Li QJ. Diversity index of mucosal resident $T$ lymphocyte repertoire predicts clinical prognosis in gastric cancer. Oncoimmunology. 2015;4(4):4-19.

17. Woodsworth DJ, Castellarin M, Holt RA. Sequence analysis of T-cell repertoires in health and disease. Genome Med. 2013;5(10):1-13..

18. Chen Y, Xu Y, Zhao M, Liu Y, Gong M, Xie C, Wu H, Wang Z. Highthroughput $T$ cell receptor sequencing reveals distinct repertoires between tumor and adjacent non-tumor tissues in HBV-associated HCC. Oncoimmunology. 2016;5(10):e1219010.

19. Liaskou E, Klemsdal Henriksen EK, Holm K, Kaveh F, Hamm D, Fear J, Viken MK, Hov JR, Melum E, Robins H. High-throughput T-cell receptor sequencing across chronic liver diseases reveals distinct disease-associated repertoires. Hepatology. 2016;63(5):1608-19.

20. Mamedov IZ, Britanova OV, Zvyagin IV, Turchaninova MA, Bolotin DA, Putintseva EV, Lebedev YB, Chudakov DM. Preparing unbiased T-cell receptor and antibody cDNA libraries for the deep next generation sequencing profiling. Front Immunol. 2013;4:456-65.

21. Bolotin DA, Poslavsky S, Mitrophanov I, Shugay M, Mamedov IZ, Putintseva EV, Chudakov DM. MiXCR: software for comprehensive adaptive immunity profiling. Nat Methods. 2015;12(5):380-1.

22. Liu X, Zhang W, Zeng X, Zhang R, Du Y, Hong X, Cao H, Su Z, Wang C, Wu J. Systematic comparative evaluation of methods for investigating the TCR $\beta$ repertoire. PLoS One. 2016;11(3):e0152464

23. Bai X, Zhang Q, Wu S, Zhang X, Wang M, He F, Wei T, Yang J, Lou Y, Cai Z. Characteristics of tumor infiltrating lymphocyte and circulating lymphocyte repertoires in pancreatic Cancer by the sequencing of T cell receptors. Sci Rep. 2015;5:13664-1372.

24. Fan Y, Li Y, Chen Y, Zhao YJ, Liu LW, Li J, Wang SL, Alolga RN, Yin Y, Wang $X M$, et al. Comprehensive Metabolomic characterization of coronary artery diseases. J Am Coll Cardiol. 2016;68(12):1281-93.

25. Alroqi FJ, Chatila TA. T regulatory cell biology in health and disease. Curr Allergy Asthma Rep. 2016;16(4):27-39.

26. Allan RS, Nutt SL. Deciphering the epigenetic code of T lymphocytes. Immunol Rev. 2014;261(1):50-61.

27. Zhou X, Nicoletti A, Elhage R, Hansson GK. Transfer of CD4(+) T cells aggravates atherosclerosis in immunodeficient apolipoprotein $E$ knockout mice. Circulation. 2000;102(24):2919-22.

28. Zhou X, Robertson AK, Hjerpe C, Hansson GK. Adoptive transfer of CD4+ T cells reactive to modified low-density lipoprotein aggravates atherosclerosis. Arterioscler Thromb Vasc Biol. 2006;26(4):864-70.

29. Chen XM, Zhang T, Qiu D, Feng JY, Jin ZY, Luo Q, Wang XY, Wu XL. Gene expression pattern of TCR repertoire and alteration expression of IL-17A gene of gammadelta T cells in patients with acute myocardial infarction. J Transl Med. 2018;16(1):189-98.

30. Foks AC, Frodermann V, Mt B, KLL H, Bot I, Zhao Y, Mv E, TJCv B, Kuiper J, GHMv P. Differential effects of regulatory $T$ cells on the initiation and regression of atherosclerosis. Atherosclerosis. 2011; 218(1):53-60

31. Gistera A, Hansson GK. The immunology of atherosclerosis. Nat Rev Nephrol. 2017;13(6):368-80.

32. Woodsworth DJ, Castellarin M, Holt RA. Sequence analysis of T-cell repertoires in health and disease. Genome Med. 2013;5(10):98-110.

33. Li Y, Xu L. Evaluation of TCR repertoire diversity in patients after hematopoietic stem cell transplantation. Stem Cell Investig. 2015;2:17-33.

34. Nikolich-Zugich J, Slifka MK, Messaoudi I. The many important facets of Tcell repertoire diversity. Nat Rev Immunol. 2004;4(2):123-32.

35. Lin Z, Qian S, Gong Y, Ren J, Zhao L, Wang D, Wang X, Zhang Y, Wang Z, Zhang Q. Deep sequencing of the $T$ cell receptor $\hat{I}^{2}$ repertoire reveals signature patterns and clonal drift in atherosclerotic plaques and patients. Oncotarget. 2017:8(59):99312-22.

36. Matsuura E, Atzeni F, Sarzi-Puttini P, Turiel M, Lopez LR, Nurmohamed MT. Is atherosclerosis an autoimmune disease? BMC Med. 2014;12:47-51.

37. De Palma R, Del Galdo F, Abbate G, Chiariello M, Calabro R, Forte L, Cimmino G, Papa MF, Russo MG, Ambrosio G, et al. Patients with acute coronary syndrome show oligoclonal T-cell recruitment within unstable plaque: evidence for a local, intracoronary immunologic mechanism. Circulation. 2006;113(5):640-6.
38. Frostegard J, Zhang Y, Sun J, Yan K, Liu A. Oxidized low-density lipoprotein (OxLDL)-treated dendritic cells promote activation of T cells in human atherosclerotic plaque and blood, which is repressed by statins: microRNA let-7c is integral to the effect. J Am Heart Assoc. 2016;5(9):e003976.

39. Hansson GK, Zhou X, Tornquist E, Paulsson G. The role of adaptive immunity in atherosclerosis. Ann N Y Acad Sci. 2000;902:53-62 discussion 62-54.

40. Six A, Mariotti-Ferrandiz ME, Chaara W, Magadan S, Pham HP, Lefranc MP, Mora T, Thomas-Vaslin V, Walczak AM, Boudinot P. The past, present, and future of immune repertoire biology - the rise of next-generation repertoire analysis. Front Immunol. 2013;4:413-28.

41. Hou D, Chen C, Seely EJ, Chen S, Song Y. High-throughput sequencingbased immune repertoire study during infectious disease. Front Immunol. 2016;7:336-47.

\section{Publisher's Note}

Springer Nature remains neutral with regard to jurisdictional claims in published maps and institutional affiliations.
Ready to submit your research? Choose BMC and benefit from:

- fast, convenient online submission

- thorough peer review by experienced researchers in your field

- rapid publication on acceptance

- support for research data, including large and complex data types

- gold Open Access which fosters wider collaboration and increased citations

- maximum visibility for your research: over $100 \mathrm{M}$ website views per year

At BMC, research is always in progress.

Learn more biomedcentral.com/submissions 